\title{
GESTÃO UNIVERSITÁRIA A PARTIR DA NARRATIVA DE PROFESSORES GESTORES DE DEPARTAMENTOS DIDÁTICOS
}

http://dx.doi.org/10.5902/2318133830806

\author{
Andiara Dewes \\ Doris Pires Vargas Bolzan \\ Universidade Federal de Santa Maria, Brasil.
}

\begin{abstract}
Resumo
Neste texto apresentam-se resultados de uma pesquisa qualitativa, narrativa e sociocultural, que teve como contexto de pesquisa uma instituição de ensino superior pública e como sujeitos os chefes de departamentos didáticos. O foco do estudo foi a dimensão categorial gestão universitária. O objetivo do estudo foi compreender o processo de desenvolvimento da gestão universitária. Destacamos que a gestão universitária é constituída e impulsionada por meio dos vieses das políticas públicas, da gestão educacional acadêmica, das estratégias e políticas organizacionais, do viés modelo de gestão concebido pela instituição e do viés contextual social, cultural e histórico. Assim, é possível afirmar que atuar como gestor em uma IES implica em compreender os processos de gestão, logo, a maneira como cada um desses vieses permeia 0 cotidiano da instituição. A gestão universitária requer ir além das ações administrativas e burocráticas, configurando-se em um processo permeado por distintos elementos que culminam na manutenção dos processos de ensino e de aprendizagem.

Palavras-chave: educação superior; gestão de departamento didático; professor gestor; narrativas socioculturais.
\end{abstract}

\section{UNIVERSITY MANAGEMENT FROM THE NARRATIVE OF TEACHERS MANAGERS OF DIDACTIC DEPARTMENTS}

\begin{abstract}
This article is a cut of a qualitative narrative sociocultural research, whose research context was a public higher education institution and as subjects the heads of didactic departments. The focus of the study presented here is the categorial dimension of university management. The objective of the study was to understand the process of development of university management. We emphasize that university management is constituted and driven by the biases of public policies, academic educational management, strategies and organizational, academic-administrative policies of the $\mathrm{HEl}$, the bias management model conceived by the institution and the social, cultural and historical contextual bias. Thus, it is possible to affirm that to act as manager in an HEl implies in understanding the management processes, next, the way in which each one of these biases permeates the quotidian of the institution. University management requires going beyond administrative and bureaucratic actions, forming a process permeated by different elements that culminate in the maintenance of teaching and learning processes.
\end{abstract}

Key-words: higher education; didactic department management; teacher manager; sociocultural narratives. 


\section{Considerações iniciais}

o nos lançarmos às leituras e estudos acerca da gestão universitária para
conhecermos o que há de pesquisa nesse campo, identificamos que a
maioria das publicações advêm na área da Administração. Compreendemos que há uma escassez de estudos que olhem para os tempos e espaços da gestão universitária a partir dos pressupostos da área da Educação, principalmente, ao considerarmos que os gestores universitários que ocupam cargos de chefia nas instituições de ensino superior - IES - públicas são, em primeiro lugar, professores. Salientando que ingressaram na instituição a fim de atuarem no âmbito da docência. Logo, a atuação como gestor estabelece-se como um novo lugar em que o docente universitário ocupa. Desse modo, entendemos como relevante estudar a gestão universitária a partir do campo educacional, especialmente, dos substratos teóricos acerca da profissão docente, do trabalho docente e da formação de professores.

Assim, a abordagem da pesquisa adotada foi qualitativa, narrativa e sociocultural. $\mathrm{O}$ contexto de investigação foi uma IES pública federal e como sujeitos tivemos os chefes de quatro departamentos didáticos. A coleta de dados foi realizada por meio de entrevista semiestruturada, organizada a partir de tópicos guia, pautada em um processo de análise interpretativo e explicativo.

Neste artigo temos como objetivo compreender o processo de desenvolvimento da gestão universitária por meio dos vieses que compõem e movimentam esse processo. Assim, este trabalho se constitui em uma contribuição teórica articulada às narrativas de professores gestores a partir do campo da Educação, acerca dos tempos e espaços da gestão universitária de uma IES pública.

\section{Pressupostos e concepções: gestão universitária em pauta}

Nas últimas décadas temos acompanhado novas, constantes e contínuas reconfigurações da vida em sociedade. Como sujeitos sociais, históricos e culturais estas configurações demandam atualizações que produzem novos modos de viver. No que tange ao panorama educacional brasileiro evidenciamos que os contextos emergentes que se salientam precisam ser levados em conta e problematizados ao pensarmos a arquitetura formativa da e na educação superior.

Os contextos emergentes da educação superior se constituem também por meio de processos sociais e culturais. Como exemplo temos as tecnologias digitais, que criam novas tendências no que diz respeito aos modos de viver em sociedade. Outra dimensão que configura esses novos contextos é oriunda das concepções e legislações que vão sendo criadas, visando a organizar a vida em sociedade, bem como cada setor que a compõem.

Nesse sentido, Squissardi (2009) aborda as perspectivas que se estabelecem no âmbito do ensino superior no Brasil, especialmente, os desafios que podem ser identificados:

A educação superior no Brasil não é um desafio novo. Além de antigo, continuará sendo um enorme desafio que se desdobra em múltiplos desafios menores, todos eles de inegável e incômoda relevância. O primeiro destes é o da compreensão das diferentes faces e dimensões daquele. O segundo é o da consciência de que, hoje mais do que ontem e muito mais do que há 30 ou 50 anos, aquele desafio exige claro e decidido 
enfrentamento. [...]. Em país como o nosso, não se pode esperar que os primeiros a entendê-lo e a enfrentá-lo sejam os analfabetos; nem os que apenas tiveram alguns anos de escolaridade ou os que cursaram o ensino fundamental completo; nem tampouco os que apenas fizeram alguns anos do ensino médio e que por razões diversas não puderam concluí-lo. Todos esses somados, perfazem em torno de $80 \%$ da população brasileira. ( $p$. 15)

Compreendendo os tempos e espaços universitários como privilegiados no que tange à produção e disseminação de conhecimentos construídos pela humanidade, identifica-se, assim, este como lócus em potencial para pensar os novos modos de ser e de estar em sociedade. Do mesmo modo, torna-se fundamental re-pensar a configuração de instituições desta natureza e sua função social na contemporaneidade.

De acordo com Cerdeira (2012),

os desafios para a gestão do ensino superior passam por significativas mudanças no Ensino Superior: surgimento de novos fornecedores de cursos [...] de novas formas de ensino (ensino virtual, educação a distância); competição para a obtenção de financiamentos públicos e de outras fontes de receita; uma mudança no perfil da população estudantil existente e a emergente. (p. 96)

Transformações impulsionadas por elementos externos às instituições repercutem em mudanças no interior delas. Entender os significados e sentidos da instituição, assim como da sua funcionalidade e papel social resulta na produção de novos sentidos, visando acompanhar a onda de atualizações que permeia o século 21 .

Nas últimas décadas diversos marcos regulatórios impulsionaram a configuração de contextos emergentes no ensino superior, principalmente por lançar novas exigências no que tangem à organização da arquitetura formativa dos cursos oferecidos, novos desafios, estabelecidos pelas repercussões das re-configurações que emergem a partir das novas organizações em diversos âmbitos e setores das IES. Cabe salientarmos que entendemos que essas mudanças que vão sendo, de certo modo, forçadas a acontecerem dentro das instituições também possibilitam identificar novas possibilidades que podem qualificar e potencializar os processos formativos, que são o principal objetivo de uma IES. Ou seja, desenvolver atividades na área do ensino, da pesquisa e da extensão, configura-se como o ambiente de formação de profissionais de diversas áreas.

As IES, especialmente aquelas de grande porte, como é o caso da que é contexto da pesquisa que desenvolvemos, são organizadas com diversos setores que atuam em distintos ramos, de modo que todos culminam na organização e funcionamento das atividades de ensino, de pesquisa e de extensão que são desenvolvidas. No caso da nossa pesquisa, enfocamos os departamentos didáticos, os quais se configuram como o setor em que os docentes são vinculados à instituição, de acordo com a sua área específica de formação e atuação, espaço no qual acontece a gestão da vida funcional dos docentes, como, por exemplo, a organização e distribuição dos encargos didáticos, que se refere a oferta das disciplinas de cada curso disponibilizadas pelo departamento e que precisam ser atendidas pelo corpo docente que compõem aquele departamento. 
Distinto de outros setores, como as coordenações de curso, que abarcam a vida acadêmica dos estudantes, os departamentos didáticos atuam, principalmente, no âmbito da vida funcional dos docentes e na oferta de disciplinas aos cursos oferecidos pela instituição, vinculados a eles.

Nessa perspectiva, compreendemos por gestão universitária a gestão dos tempos e espaços formativos, no âmbito da educação superior, abarcando nesse processo o viés administrativo e burocrático, assim como o viés educacional (Dewes, 2017).

Esse é o contexto de atuação do professor universitário. Além de atuar com o âmbito da formação, especificamente, na docência, a pesquisa e a extensão são campos de atuação que tem como objetivo a composição do tripé universitário que é a atuação nessas três dimensões de modo articulado com o objetivo de proporcionar tempos e espaços formativos de excelência. Pesquisas recentes de Bolzan (2016); Dewes (2017), indicam a atuação no âmbito da gestão universitária em IES como um novo desafio aos docentes universitários, principalmente, ao considerarmos os contextos emergentes.

Estes contextos são caracterizados, principalmente, pelos marcos regulatórios e pelas políticas públicas das últimas décadas, como a expansão das instituições e do número de vagas, a criação do sistema de reserva de vagas/cotas, bem como de aspectos decorrentes da incorporação das tecnologias no cotidiano universitário como, por exemplo, ambientes virtuais de ensino aprendizagem, tecnologias assistivas, dispositivos móveis: notebooks, smartphones, tablets.

Nessa direção, entendemos que a gestão sempre foi um lugar de possível atuação do docente, no entanto, acreditamos que essa conjuntura atual do ensino superior, amplificada e complexificada pelas transformações ocorridas recentemente e que repercutem no cotidiano das instituições - incorporação das novas tecnologias, aumento de vagas de ingresso, criação de cursos, sistema de reserva de vagas/cotas, internacionalização -, tornaram o trabalho dos professores gestores mais complexo. Desse modo, há uma necessidade de profissionalização da gestão universitária, ou seja, no caso dos professores que ocupam cargos de chefia nas IES é essencial que a instituição disponha de um espaço para preparar o docente que atua ou irá atuar como gestor a desempenhar esse papel. Atrelada a essa necessidade está a de qualificar os processos de gestão, especialmente visando a otimizar e potencializar as ações, atividades e mecanismos que compõem o funcionamento dos tempos e espaços de gestão.

Para compreender a conjuntura que compõe o contexto de pesquisa, articulado com as recorrências evidenciadas nas narrativas dos professores gestores entrevistados construímos, no processo de análise, interpretativo e reflexivo, a dimensão categorial gestão universitária. Esta dimensão foi definida pelas recorrências, desafios e exigências do ser gestor; produção de sentido da e na gestão; gestão do departamento; articulação com a docência; contextos emergentes na educação superior e relações interpessoais (Dewes, 2017).

Nas narrativas, os professores gestores entrevistados evidenciaram que a identificação das exigências e dos desafios caracteriza o início do processo de atuação. Nos excertos que seguem essa perspectiva é explicitada: 
De mediar esses conflitos, de obedecer às normas instituídas, fazer valer nas reuniões as normas do colegiado, as normas o próprio Regimento do Centro e dar prosseguimento a toda a vida dos professores desde assim, por exemplo, qualificação profissional, afastamento de professores, diárias e passagens, tudo é deliberado no coletivo, não decido nada, nada, nada sozinha. A minha gestão é participativa, é democrática, e eu faço questão de tudo aquilo que eu estudo lá na gestão colocar em prática na dinâmica do dia-a-dia. Desde assim, vem e pede por favor, digo vamos colocar no grupo, o grupo que vai decidir e a maioria que vale. Nada eu decido, olha 18 anos de decisões democráticas, participativas e procurando sempre ser justa e dar de fato um tratamento igualitário não importa se foi diretor, se foi isso, se foi aquilo, para min são todos colegas iguais e até os inimigos eu faço as mesmas coisas, eu não prejudico em nada, eu dou a mesma chance de misericórdia perdão e regeneração do que aqueles que vivem até querendo agradar, dar presentinho e coisas assim, que, às vezes, eu digo olha, dá para outra pessoa, não preciso, não quero, sabe, às vezes, para não ter aquela coisa ai está sendo presenteada, não. (Professor gestor 1).

Tem necessariamente duas dimensões: participar o que é normal e é inerente ao cargo da gestão do processo e, felizmente, isso é uma coisa importante de a gente salientar, felizmente hoje a universidade e aí também entra a dimensão política é diferente de outros espaços de gestão de empresas, por exemplo, todos os espaços da universidade eles são espaços democráticos, tanto é que eu sou chefe do Departamento porque é um cargo eletivo eu sou eleito pela comunidade, e assim todos os demais representantes, então, os espaços universitários são espaços democráticos enquanto espaço democrático tem necessariamente $o$ enfrentamento político porque ali existem imposições. Eu tenho uma visão de mundo, eu tenho uma filosofia de vida, eu tenho uma visão da história, eu tenho uma visão do que é a universidade, mas existem conflitos, colegas que têm outra visão. Então nesses espaços democráticos entra a dimensão política de o gestor trabalhar na perspectiva de consolidar aquela visão de universidade. No meu caso e de outros colegas era exatamente cada vez abrir mais a universidade como espaço de participação e todas essas instâncias assim como espaços políticos sim de definição, então essa dimensão política dimensão administrativa. (Professor gestor 2).

Sim, muitos, muitos desafios a gente têm na chefia. Por isso que eu acho que uma questão para a gente estar em uma chefia é o respeito com o colega, mas também é de você ter uma atitude de ser gestora. Isso não é de impor nada aos colegas. Contudo, se eu estou na posição de gestora eu tenho que assumir um papel de gestora, eu preciso assumir esse papel de gestora. E é um desafio isso. Então, não de impor, mas quais são as estratégias que eu posso utilizar como gestora tendo ética, tendo respeito aos colegas e um trabalho democrático dentro desse espaço que democracia não é fazer o que eu quero ou o que o outro quer, não é isso. Então, é aquilo de você colocar a situação e a partir disso pesar junto com os colegas ou, então, as tomadas que a gente tem que ter dentro daquilo que se tem de elementos para poder colocar em funcionamento o setor. [...]. Eu acho que ser gestor muito mais do que um curso de preparação a gente aprende e a gente precisa ter esses elementos de ética, de respeito, de compromisso, em primeiro lugar, ser democrático. (Professor gestor 4). 
A partir das manifestações dos gestores constatamos que eles identificam como sendo um dos desafios a mediação de relações interpessoais. Essa mediação configurase como um dos papeis mais frequentes dos gestores. As suas narrativas permitem-nos evidenciar que pautam sua atuação no princípio da democracia e que entendem que a maneira como se relacionam com os seus colegas deve ser pautado nessa perspectiva.

Nessa direção, compreendemos que ao mobilizarem as concepções, os significados e os sentidos que possuem e trazem em sua bagagem ao chegarem a um cargo de gestão os docentes constroem os saberes docentes relativos a essa função. Esses saberes são construídos no transcorrer da atuação como gestor impulsionados pelas exigências e pelos desafios com que o professor gestor se depara. Desse modo, os saberes docentes da gestão são produzidos no processo de gerenciamento, por isso, entendemos que há um processo dinâmico que acontece se retroalimentando pelas experiências e vivências que o docente tem ao atuar no âmbito da gestão.

Nesse sentido, identifica-se como necessário ir além dos conhecimentos técnicos e organizacionais da instituição e de suas regulações, saber e compreender a vida pulsante da instituição. É entender que a gestão não se restringe ao atendimento das demandas burocráticas. Portanto, é fundamental reconhecer e atender as demandas emergentes dos contextos sociais e culturais, construídos historicamente.

A amplitude e complexidade de IES exige dos gestores, inicialmente, um conhecimento do ambiente existente no interior da instituição para que, então, compreendam que as políticas elaboradas, resultando em programas e projetos (Reis, 2003). Ou seja, o gestor também precisa compreender que influências externas repercutem no ambiente interno da universidade. Conhecer e compreender as dinâmicas externas e as internas, bem como o quanto e como cada uma repercute na gestão tornam ainda mais complexa a função do gestor e sua atuação. É essencial que ele conheça seu contexto de atuação, bem como os sujeitos que pertencem a este contexto.

Esse conhecimento torna-se essencial para que possa pensar, no âmbito da gestão, em ações estratégicas no que tange à atuação e estruturação da instituição. A organização ou construção de estratégias pressupõe planejamento para que as decisões tomadas e as ações efetivadas possam ir de maneira satisfatória e adequada ao encontro das demandas que emergem do contexto. Por isso, gestão implica em entendimento acerca da instituição, principalmente no que tange à sua manutenção, e dos contextos sociais e culturais construídos historicamente. Nessa direção, Goldchleger, Ivoglo e Colombo (2013) destacam que

o estilo de gestão brasileiro é proveniente de uma história de administração "incremental", em resposta às mudanças no cenário externo. As estruturas organizacionais, os sistemas, os novos produtos ou cursos no sistema educacional foram melhorias feitas em relação aos existentes anteriormente. No cenário atual, as universidades não estão imunes às mudanças e às incertezas que vêm ocorrendo nos campos econômico, tecnológico, político, cultural, social e educacional, o que exige dessas organizações maior rapidez e capacidade de resposta às demandas externas, assim como melhor desempenho, condições fundamentais para sua sobrevivência. (p. 199) 
Desse modo, sobreviver no contexto atual significa reconhecer as mudanças que ocorrem e compreender que são tanto no âmbito de configurações de estruturas e organizações, quanto de modos de ser e de estar. Assim, articular-se às mudanças implica em tentar compreendê-las e buscar usufruí-las, qualificando e potencializando, especialmente, nos contextos universitários, os tempos e espaços formativos, bem como os processos de gestão da instituição.

É primordial entender que a gestão não é feita por um indivíduo apenas. A coletividade, a equipe de gestão de um determinado setor é fundamental, pois o processo de gestão é compartilhado com todos aqueles que vivem os tempos e espaços universitários. Salientamos novamente o papel do gestor de mediar e gerenciar a sua equipe de tal modo a promover a consolidar uma articulação e interlocução com as exigências, os desafios e as possibilidades que se estabelecem nesse contexto.

Acerca desse aspecto Reis (2003) aponta que "por isso a arquitetura organizacional pode ser determinante para as instituições enfrentaram os desafios advindos da complexidade do sistema de ensino superior" (p. 29). A arquitetura organizacional precisa dar condições para que essa dinamicidade dos processos de gestão aconteça. $O$ mesmo autor define que

o clima é resultado da cultura institucional que pode ser entendida como o conjunto de crenças e valores compartilhados na instituição e que interferem no estilo de gestão e de liderança. [...]. O fortalecimento dos valores contribui para a convergência dos objetivos. É necessário que a IES divulgue sua missão, visão e valores, que esclareça as metas para que possam ser compreendidos. Quando as metas são estabelecidas a partir da participação dos diversos setores da instituição, a probabilidade de sucesso na sua implementação é significativa. Da mesma forma, as mudanças culturais exigem um esforço de discussão e esclarecimento, para que ocorra a congruência das atitudes individuais. (Reis, 2003, p. 36)

Considerando a amplitude e a complexidade de uma IES, é fundamental uma equipe consciente de seu papel, tanto no âmbito individual como no coletivo, visando a consonância com a missão, os objetivos, o perfil de instituição, assim como a proposta e filosofia de atuação definidos institucionalmente.

Por outro lado, precisamos levar em conta que a cultura institucional está presente e, inclusive, é consolidada em diversos âmbitos da instituição. A perspectiva de gestão que vai para além de apenas tarefas burocráticas e administrativas resulta na necessidade de construir novas posturas de atuação e, especialmente, de compreensão sobre esse tempo e espaço formativo que é a educação superior.

Nessa direção, Sousa (2011) destaca que

atender a estes desafios significa aceitar mudanças, e um primeiro aspecto a ser explicitado diz respeito à dificuldade de promovê-las nas IES. Além da tradição estabelecida para manter as relações de poder extensamente discutidas ao longo dos anos, e mesmo das turbulências que sinalizam a necessidade de enfrentar novos desafios, essas instituições mantêm culturalmente uma grande resistência a alterar suas condutas e seus modelos cristalizados. [...]. São inúmeros os desafios a serem enfrentados, 
os quais requerem de cada IES a capacidade de encontrar o conjunto de fatores que definem seu potencial e, a partir daí, desenhar seus processos, (re)definir seus recursos e analisar se os resultados previstos estão de acordo com os valores organizacionais. (p. 97)

Compreender a cultura organizacional é essencial para que os gestores consigam constituírem-se em líderes de equipes que compreendem que trabalham em setores específicos, desempenham atividades específicas, mas que, principalmente, trabalham em prol da manutenção dos tempos e espaços formativos de qualidade na instituição.

Nessa perspectiva, o formato da gestão concebido e posto em prática em cada instituição é também uma das dimensões que precisa ser compreendida por todos os envolvidos, pois somente com o comprometimento de todos é que a gestão, tal como concebida, poderá ser efetivada.

Acerca desse aspecto, Sousa (2011) salienta que "o formato de gestão de uma IES é definido a partir das políticas institucionais assumidas, isto é, seu padrão de atuação é organizado de acordo com a missão, com as crenças e com os valores estabelecidos pelos líderes responsáveis" (p. 99). Logo, essas definições da instituição, como as crenças e valores, e que pautam as prioridades na IES, consolidam-se quando poderem ser identificados incorporados nas práticas dos profissionais que atuam nos vários âmbitos da instituição.

Desse modo, evidencia-se que a atuação do professor gestor engloba, também, a gestão dos recursos humanos e financeiros. Logo, compreender a atuação de gestor e as implicações que esta função possui no âmbito da instituição. Assim, com a complexidade dessa atuação, mobiliza-o a construir saberes que possam lhe permitir desempenhar essa função. Os professores gestores, ao atuarem como chefes de departamentos didáticos, deparam-se com o desafio de construírem saberes acerca dessa dinâmica, buscando aprender como gerenciar os interesses e necessidades oriundos de diferentes vieses, os quais definem e movimentam a gestão pública.

Diante dessa conjuntura, vejamos o que os professores gestores entrevistados falam acerca do que compreendem como sendo a gestão universitária:

Acho que essa é uma questão fundamental, porque infelizmente na universidade as pessoas têm um equívoco muito grande: acham que gestão universitária é gestar o processo burocrático. E eu na minha concepção, isso eu sempre disse para o meus colegas de Departamento quando eu me candidatei à chefia, é que eu ia ser um gestor do processo básico, o instituído a questão burocrática, mas também eu penso que o gestor universitário ele tem a sua dimensão da prática política porque esses espaços, o espaço de Colegiado Departamental, Colegiado de Curso, Conselho de Centro e Conselhos Superiores eles não são apenas espaços para definir aquilo que já é instituído, são espaços de discussões, de debates políticos até para orientar o caminho da própria universidade. (Professor gestor 2).

A gestão universitária, na minha concepção, ela tem que ter transparência da sua organização e saber quais as atribuições de cada setor. E que as decisões ao serem tomadas sejam coletivas e que o executor respeite essa decisão e não seja autoritário. Eu conheço muitos gestores, entre aspas, que se diz "gestores", reúne uma Comissão, a Comissão dá uma decisão, apresenta sugestões e aí quando, agradece, e quando ele vai 
para discurso ele faz outra coisa. Então, a gestão é aquilo um espaço aberto de transparência das decisões que são tomadas, é público, não tem que estar fechado, então essa é a minha concepção, onde as pessoas e todas as pessoas tenham a responsabilidade de saber o que está sendo decidido. (Professor gestor 3).

Eu acho que, assim, o que ela é e o que ela deve ser eu acho que a gente sempre tem questões a serem pontuadas e a serem consideradas. Eu penso que uma gestão, uma gestão no setor público, principalmente, como é a universidade, independente da instância, seja reitoria, seja direção de centro, seja chefia do departamento, ela tem que ser de uma forma bastante equitária, a gente ter o respeito com as decisões que são tomadas nas instâncias e ser conduzido dessa forma. Acho que é democracia e democracia eu não entendo que a gente faz o que a gente quer. Democracia eu entendo que quando um grupo, quando é colocado uma discussão no grande grupo, quando a maioria decide por algo, isso deve ser respeitado. Ou então quando o setor que é responsável por tomar algumas decisões quando ele toma que isso seja respeitado. Eu acho que em uma administração pública isso tem que ter. (Professor gestor 4).

A partir de suas narrativas é possível evidenciarmos que as suas ações como gestores são pautadas nas concepções do que é gestão universitária. Concepções distintas que foram construídas no decorrer das trajetórias pessoais e profissionais, especialmente, a partir das vivências formativas em tempos e espaços de gestão.

Mediar relações é possível ser indicada por meio da fala do gestor 1 como sendo o papel do gestor. Pois no âmbito da gestão de departamentos didáticos as diferentes ideias, as divergências e, especialmente, as relações que se estabelecem entre os colegas constituem uma das dimensões de constituição da gestão. Já o professor gestor 2 expressa a necessidade de levar em conta a dimensão da prática política na atuação do gestor. Salienta, também, o aspecto que tange à formação para atuação como gestor. Dinâmicas de processos de tomadas de decisões pelo coletivo e o modo como esse processo é conduzido pelo gestor é evidenciado na fala do professor gestor 3 . 0 professor gestor 4 aborda que considera fundamental ter presente nas dinâmicas desenvolvidas no âmbito da gestão o aspecto público e democrático. É possível evidenciarmos que indica a existência de controvérsia no que tange ao que acredita ser e o que é na prática a gestão universitária.

Ao abordarem aspectos específicos em suas narrativas, os gestores nos permitem identificar a complexidade e amplitude da gestão universitária, especialmente, nas IES públicas. Logo, esse cenário contemporâneo que se configura nas IES precisa de gestores comprometidos com a instituição e sua manutenção, bem como com a qualidade da formação promovida pelos cursos oferecidos.

Nessa direção, a possibilidade de construção de saberes acerca da gestão permite ao professor gestor compreender que está imbricado em sua função a de propositor, pautando-se em um reconhecimento de que a função de gestor está para além de ser apenas burocrática.

O professor gestor 2 expressa essa perspectiva na narrativa que segue:

Na verdade, tu não estás ali só para avalizar homologar o que está posto.

O gestor a função e aí que é um espaço importantíssimo, o espaço político do chefe de departamento, do coordenador de curso, ele é um gestor que 
está em um cargo, mas ele também é importante para definir o futuro da própria instituição. Mas para ti ser um, digamos assim, um gestor que trabalhe nessa ótica de propor políticas, de questionar as próprias formas os modos operantes da instituição tu tem que ter conhecimento político para isso. E é fundamental para os cargos de gestão e eu diria para coordenador, para chefe de departamento, diretor de Centro. (Professor gestor 2).

Nessa direção, políticas e programas públicos educacionais, assim como as relações que se estabelecem com os órgãos do governo e as agências de fomento, também precisam ser compreendidos como um dos vieses que constituem e permeiam as IES, pois, não há como falar de gestão sem considerar as políticas públicas do âmbito educacional. Aspectos e elementos de gestão dos tempos e espaços formativos são, principalmente, definidos e impulsionados por marcos regulatórios e orientadores disseminados via políticas e programas públicos ou governamentais.

De acordo com Tofik (2013),

as concepções relativas às políticas educacionais têm passado por mudanças profundas nas últimas décadas, mais precisamente desde 0 final do século $X X$ até os nossos dias. As formas de se conceituar, organizar a promover a educação formal vêm se transformando e exigindo novas respostas a antigos problemas. Com foco nas perspectivas políticoinstitucionais, na relação docente-discente, nos ambientes e mídias e nas condições de contorno da própria comunidade em que se constitui, a instituição de ensino superior (IES) não pode e nem consegue mais permanecer no pedestal de singularidade acadêmica em que um dia se postou. Faz-se necessário conceber uma IES que venha a atender às efetivas demandas de uma sociedade global, rompendo barreiras e limitações; faz-se necessário, ainda, reinventá-la, levando-a a conquistar novos espaços e tempos, sem que perca a identidade, imprimindo-lhe um caráter de contemporaneidade. (p. 104)

Assim, evidencia-se que os contextos emergentes na educação superior repercutem também nos tempos e espaços da gestão, sendo a estes estabelecidas a necessidade de serem pensados para além do atendimento de exigências de programas e políticas públicas, pois as demandas sociais e globais tornam-se salutares e precisam ser englobadas no cotidiano das instituições. Isto, principalmente, para que a universidade promova a manutenção do seu papel e sua relevância social na contemporaneidade.

Configuram-se, nesse cenário, novas exigências a delinear novos desafios que impulsionam à atuação nesse contexto de mudanças contínuas, de tal modo a possibilitar a identificação e elaboração de novas possibilidades.

Alcançar o sucesso torna-se ainda mais complexo nos tempos atuais, pois integrar competências administrativas e acadêmicas estabelece-se como primordial para a IES visando a sua manutenção. A otimização e qualificação das atividades que constituem o tripé de atuação, ensino, pesquisa e extensão, bem como a desejada indissiociabilidade entre estes elementos caracterizam a busca pelo sucesso da instituição.

Nessa direção, torna-se primordial que os processos de gestão sejam otimizados e potencializados. Isso estabelece como exigência que os integrantes de equipes gestoras, especialmente que os gestores sejam preparados para desempenharem as funções no 
âmbito administrativo da instituição. Castro (2013) destaca que não há mais espaço para o amadorismo, assim "a qualificação dos profissionais atuantes na gestão, seja ela acadêmica ou administrativa, é necessária e obrigatória" (p. 196).

A gestão da infra-estrutura de uma IES, tanto física, quanto de pessoal, reflete na implementação e manutenção das propostas formativas da instituição, assim, tanto o viés acadêmico, quanto o administrativo permeiam os tempos e espaços de gestão. Desse modo, configura-se a possibilidade de criação e de produção de novos modos de ser e de estar no âmbito da governança universitária, logo a necessidade emergente de inovação no que tange ao gestar os tempos e espaços formativos. Essa perspectiva recai na exigência de entendimento e comprometimento de todos os envolvidos nesse processo, pois, a consolidação de uma cultura de gestão é essencial na construção do sucesso da instituição.

Nesse sentido, evidenciamos que diferentes dimensões movimentam a gestão de departamentos, tendo-se como eixo central da gestão da IES a gestão universitária. $\mathrm{Na}$ figura que segue apresentamos uma representação de como entendemos o processo que se estabelece.

Figura 1 -

Esquema representativo da espiral do desenvolvimento da gestão universitária.
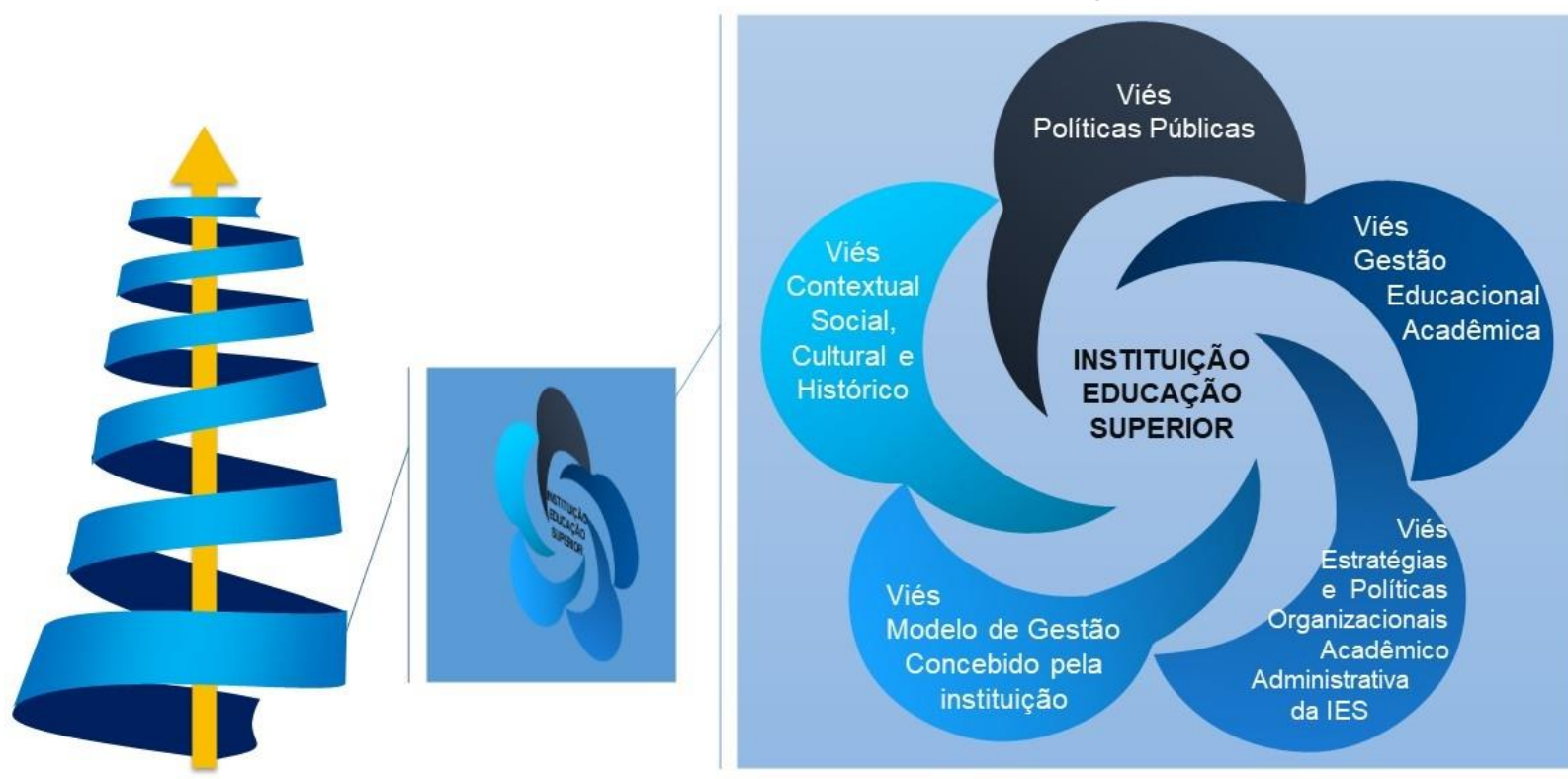

Fonte: Dewes 2017.

Compreendemos que a gestão da IES é constituída pelo viés do contexto social, cultural e histórico, viés das políticas públicas, viés da gestão educacional/acadêmica, viés estratégias e políticas organizacionais acadêmico administrativa da instituição e o viés modelo de gestão concebido pela IES. Esses vieses põem em movimento o processo de gestão e desenvolvimento da IES, ou seja, dos espaços formativos no âmbito da instituição pública de educação superior. 
Nessa direção, entendemos que a gestão do departamento didático também está pautada em processos complexos e dinâmicos permeados por elementos e dimensões específicos e peculiares que vão, concomitantemente, se articulando, amplificando-se e tornando-se mais complexos.

Diante desse cenário, Souza (2011) indica que o

desafio de todos os que atuam nas IES é entender que o modelo arraigado há tanto tempo requer uma revisão. É preciso ampliar a qualificação do corpo docente para além da titulação e do regime de trabalho, estimulando o professor a ver o ensino como planejamento e seleção de experiências de aprendizagem que permitam ao aluno reorganizar seus esquemas mentais e ser capaz de estabelecer relações entre o conhecimento que possui e os novos, chegando a novos significados. (p. 109)

Os processos de ensino e de aprendizagem nos tempos atuais precisam ser repensados. Do mesmo modo os tempos e espaços formativos em uma IES precisam ser organizados de modo a serem eficientes no âmbito educacional e no organizacional.

Nesse sentido, Nunes (2013) destaca que

as instituições de ensino, por muitos anos, ainda lidarão com a relação ensino-aprendizagem na sala de aula. O que irá mudar são as definições de ensino, de aprendizagem, de sala e de aula. Ensino não será apenas tarefa do professor e ministrado por instituições. Aprendizagem não seguirá apenas o currículo obrigatório prescrito e tende a ser sob demanda. Sala poderá ser física, virtual, ou ambas, na instituição, em casa ou no trabalho. Aula será uma experiência de múltiplas inteligências, incluindo as expressões cinestésicas totais de texto, imagem, som, odor, tato em ambientes reais, mediadas por tecnologias ou holográficas. ( $p$. 278)

Qualificar e potencializar os processos de ensino e de aprendizagem repercute nos processos formativos que acontecem no âmbito da IES. Desenha-se uma perspectiva em que emerge a necessidade de criação de novas estratégias, ou mesmo atualizar as já existentes, visando a otimizar e dinamizar de modo a promover a potencialização dos processos formativos. É fundamental que essa dimensão seja englobada nas discussões e problematizações que acontecem no âmbito da gestão, pois é onde são definidos e propostos orientações e a manutenção dos tempos e espaços educativos em nível de ensino superior. Nessa perspectiva, o gestor precisa conhecer e compreender esses aspectos que compõem e permeiam o fazer da educação superior.

$\mathrm{Na}$ narrativa que segue o professor gestor 2 expressa suas percepções acerca da conjuntura nacional abarcando tanto as condições de trabalho nesse nível de ensino como a qualidade do ensino:

O que era ontem, por exemplo, quando eu entrei o que é hoje quando tu estás aqui, entendeu?! É uma diferença substancial. $O$ nosso departamento [...] quando eu entrei ali era o primo pobre. Hoje é uma produção de massa crítica fantástica. Por quê? O departamento evoluiu, o Centro de Educação evoluiu, a concepção sobre formação de professores evoluiu, [...], a concepção é outra. De qualificação, de conhecimento de ponta. [...]. Tanto é que a pós-graduação ali é uma das notas mais altas do $\mathrm{CNPq}$ e da Capes. Agora se começar com essa coisa de enforcamento de 
orçamento de política de cortes aí nós vamos para um período difícil para a universidade. Começa pela natureza das relações de trabalho, de 2013 para cá, [...]. Tu tens um cara que tem um curso, eu já vi pessoas falando: "mas com a qualificação que tenho eu não vou trabalhar no Brasil". Ele vai embora. O que nós fizemos a vida inteira, até décadas atrás, que era exportar massa crítica, depois nós invertemos porque o Brasil começou a valer a pena o cara trabalhar aqui, daqui a pouco nós vamos, isso que eu te disse que a gente nunca imaginou que isso poderia acontecer. [...], tu, nós que somos do interior, quanto mais pessoa formada e volta para o interior tu areja. Agora deixa o cara lá na pequena propriedade... [...]. Entendeu?! Não traz aquele vivente! E assim é o Brasil inteiro. Então isso é uma concepção de poder é uma concepção de sociedade e exatamente eles querem é castrar possibilidade do acesso ao conhecimento. Quer queira quer não, como eu te disse, conhecimento é poder. (Professor gestor 2)

Evidenciamos, por meio da fala do professor gestor 2, que há convergências e também divergências de movimentos que permeiam a conjuntura da educação superior no Brasil, atualmente. De um lado, movimentos impulsionadores de democratização do ensino e, de outro lado, movimentos buscando manter o controle sobre essa expansão. Essa percepção do docente nos remete a aspectos que nos remontam às épocas, não tão distantes, em que o acesso ao ensino superior era privilégio para uma elite. Cabe ressaltar que entendemos que ainda é um privilégio para alguns, mesmo que o acesso esteja sendo um pouco mais democratizado, ainda é uma elite que consegue entrar e se manter até o final da formação em uma IES pública. O professor aponta também a perspectiva que se desenha aos novos professores no que tange às condições de trabalho e mesmo aspectos relacionados à carreira do magistério de nível superior.

\section{Considerações finais}

Apresentamos, neste trabalho, um panorama sobre pressupostos e concepções acerca dos tempos e espaços da gestão universitária em uma IES pública, por meio de uma articulação teórica com as narrativas de professores gestores. Pautando-nos no objetivo estabelecido para este artigo, compreender o processo de desenvolvimento da gestão universitária, evidenciamos que os vieses que compõem e movimentam esse processo, são: viés das políticas públicas; viés da gestão educacional acadêmica; viés das estratégias e políticas organizacionais acadêmico administrativo da IES; viés do modelo de gestão concebido pela instituição e viés do contextual social, cultural e histórico.

Acerca do viés das políticas públicas identificamos que estas implicam diretamente na dinâmica organizacional de uma instituição, pois é por meio delas que aspectos da organização, da oferta e da manutenção dos cursos, bem como do ingresso e egresso de estudantes são definidas. Mesmo que a instituição tenha autonomia para definir e organizar os diversos âmbitos da instituição, orientações que são propostas por meio das políticas, em nível nacional, precisam ser atendidas pela IES. Assim, mesmo que a IES tenha sua dinâmica organizacional e suas definições normatizadas acerca do seu funcionamento e manutenção dos tempos e espaços formativos, como, por exemplo, a criação de reserva de vagas/cotas lançou novas exigências às IES quanto ao ingresso de novos estudantes. Desse modo, estabeleceram-se à gestão Universitária novas exigências e desafios que precisavam ser atendidas.

\begin{tabular}{|l|l|l|l|l|l|}
\hline Regae: Rev. Gest. Aval. Educ. & Santa Maria & v. 7 & n. 15 & Maio/ago. 2018 & p. 39-53
\end{tabular}


No que tange ao viés da gestão educacional acadêmica esta abarca elementos que se referem a maneira como as exigências e os desafios são abordados, bem como a construção e identificação de novas possibilidades, tanto no que diz respeito ao funcionamento administrativo da instituição, como acadêmico.

O viés das estratégias e políticas organizacionais acadêmico administrativo da IES engloba os mecanismos que são usados e produzidos pelos gestores para organizar e garantir o funcionamento nesse âmbito institucional.

Acerca do viés do modelo de gestão concebido pela instituição compreendemos que esse corresponde ao entendimento que os gestores têm sobre o que é gestão e quais os princípios que pautam a sua atuação, além do papel e das suas funções na instituição.

Já o viés do contextual social, cultural e histórico traz ao processo de desenvolvimento da gestão universitária as demandas que emergem dessa conjuntura. Atualmente temos como uma das características mais evidentes a tecnologia, que além de estar sendo incorporada a todo os âmbitos do contexto sociocultural, chega aos tempos e espaços da educação superior, como, por exemplo, a oferta de cursos na modalidade à distância, a incorporação de ambientes virtuais de ensino-aprendizagem nos processos de ensino e de aprendizagem, as tecnologias assistivas (estas articulandose a um público especifico que necessita desses recursos), dentre tantos outros elementos que configuram as novas exigências e desafios, assim como, também, novas possibilidades.

A identificação e compreensão de cada um desses vieses possibilita entender como cada um influencia o processo de desenvolvimento da gestão universitária. Compreender que esse processo de desenvolvimento é composto por diferentes elementos e aspectos implica em reconhecer a amplitude e complexidade da gestão universitária, bem como do trabalho dos gestores universitários.

Assim, é possível afirmar que atuar como gestor em uma IES implica em compreender os processos de gestão, logo, a maneira como cada um desses vieses permeia o cotidiano da instituição. A gestão universitária requer ir além das ações administrativas e burocráticas, configurando-se em um processo permeado por distintos elementos que culminam na manutenção dos processos de ensino e de aprendizagem, que é o eixo central de uma instituição de ensino.

\section{Referências}

BOLZAN, Doris Pires Vargas et al. Aprendizagem da docência: processos formativos de estudantes e formadores da educação superior. Relatório final do projeto de pesquisa $n$. 032835, GAP/CE/UFSM, 2016.

CASTRO, Alessandro de. Gestão financeira: a sustentabilidade financeira e a interação acadêmica nas instituições de ensino superior. In: COLOMBO, Sonia Simões (org.). Gestão universitária: os caminhos para a excelência. Porto Alegre: Penso, 2013, p. 197197.

CERDEIRA, Luisa. Os desafios da gestão do ensino superior: algumas tendências e tensões. In: CUNHA, Maria Isabel da; BROILO, Cecilia Luiza (orgs.). Qualidade da educação superior: grupos investigativos internacionais em diálogo. Araraquara: Junqueira \& Marin, 2012, p. 79-98. 
DEWES, Andiara. Gestão universitária: departamentos didáticos e contextos emergentes da educação superior pública. 2017. 230f. Santa: UFSM, 2017. Monografia (especialização em Gestão Educacional). Centro de Educação, Universidade Federal de Santa Maria.

GAUTHIER, Clermont et al. Por uma teoria da pedagogia: pesquisas sobre o saber docente. ljuí: Unijuí, 2013.

GOLDCHLEGER, Lizika Pitpar; IVOGLO, Milana; COLOMBO, Sonia Simões. Gestão do capital humano nas instituições de ensino superior. In: COLOMBO, Sonia Simões (org.). Gestão universitária: os caminhos para a excelência. Porto Alegre: Penso, 2013, p. 198220.

NUNES, Mekler Nichele. Dos passos estratégicos aos caminhos do marketing educacional. In: COLOMBO, Sonia Simões (org.). Gestão universitária: os caminhos para a excelência. Porto Alegre: Penso, 2013, p. 263-279.

REIS, Fábio José Garcia dos. Perspectivas da gestão universitária. Taubaté: Cabral, 2003.

SOUSA, Ana Maria Costa de. Gestão acadêmica atual. In: COLOMBO, Sonia Simões; RODRIGUES, Gabriel Mario. Desafios da gestão universitária contemporânea. Porto Alegre: Artmed, 2011, p. 97-110.

SQUISSARDI, Valdemar. Universidade brasileira no século XXI: desafios do presente. São Paulo: Cortez, 2009.

TOFIK, Denise Sawaia. A gestão acadêmica nas instituições de ensino superior. In.: COLOMBO, Sonia Simões (org.). Gestão universitária: os caminhos para a excelência. Porto Alegre: Penso, 2013, p. 104-116.

Andiara Dewes é licenciada em Pedagogia e especialista em Gestão Educacional pela Universidade Federal de Santa Maria. Estudante do Curso de Mestrado em Educação e do curso de licenciatura em Educação Especial na mesma instituição. Endereço: Rua General Neto, 180/1003 - 96050-240 - Santa Maria - RS - Brasil. E-mail: andiaraeduc@gmail.com.

Doris Pires Vargas Bolzan é professora no Departamento de Metodologia de Ensino do Centro de Educação da Universidade Federal de Santa Maria. Endereço: Avenida Roraima, 1000 - 97105-900 - Santa Maria - RS - Brasil. E-mail: dbolzan19@gmail.com.

Recebido em 11 de janeiro 2018

Aceito em 7 de abril de 2018. 